\title{
STUDI POTENSI DEBIT DAN TINGGI JATUH AIR PADA SALURAN IRIGASI UNTUK MENDUKUNG KEBUTUHAN ENERGI LISTRIK KAWASAN EKOWISATA DI DESA SRIHARJO
}

\author{
Ahmad Fachri ${ }^{1}$, Rita Dewi Triastianti, Rosiana Indrawati \\ Email :afachri960@gmail.com \\ Teknik Energi, Institut Teknologi Yogyakarta
}

\begin{abstract}
ABSTRAK
Salah satu sumber energi terbarukan adalah energi air (air). Jika pemanfaatan energi air (hidro) ditargetkan untuk mencapai $4 \%$ dari penggunaan energi nasional pada tahun 2025. Untuk mencapai target ini, perlu untuk meningkatkan pemanfaatan sumber daya air (hidro) yang tersebar di seluruh Indonesia sebagai sumber energi terbarukan. Salah satu kategori pemanfaatan sumber daya air yang menjanjikan sebagai energi terbarukan (listrik) adalah Pembangkit Listrik Tenaga Mikro Hidro (PLTMH) (Marfudin, 2016). Kincir air adalah sarana untuk mengubah energi air menjadi energi mekanik dalam bentuk torsi pada poros roda. Roda air breastshot adalah kombinasi dari tipe overshot dan undershot dilihat dari energi yang mereka terima.

Data dikumpulkan di Dusun Palemadu, Desa Sriharjo, Kecamatan Imogiri, Kabupaten Bantul, Yogyakarta karena tidak adanya data sebelumnya, peneliti melakukan observasi dan metode literatur dengan mengukur kecepatan aliran irasional sebelum memasuki pabrik, dan ukuran utama air. pabrik.

Total energi yang dihasilkan oleh roda air Breashshot pada saluran irigasi dengan efisiensi adalah 50,49\% dengan laju aliran 1,8 m3 / dtk, head adalah 0,3 kepadatan air $1000 \mathrm{~kg} / \mathrm{m} 3$ dan gravitasi 9,81 diperoleh dengan daya listrik sebesar 267,46 watt. Dengan total daya 267,46 watt termasuk dalam jenis Pembangkit Listrik Tenaga Air Picohidro, di mana daya listrik picohidro adalah <500 watt. Desa Sriharjo adalah sebuah desa yang terletak di kawasan ekowisata dan pertanian. Daya yang dihasilkan dari roda air Breastshot tidak hanya untuk penerangan jalan, mereka juga dapat digunakan untuk mengusir hama yang menyerang petani padi.

Kata kunci: Studi potensi, laju aliran, debit, kincir air, saluran irigasi, ekowisata.
\end{abstract}

\section{STUDY OF THE DEBIT AND HIGH FALL OF WATER IN THE IRRIGATION CHANNEL TO SUPPORT THE ELECTRICAL ENERGY NEEDS OF ECOWISM IN SRIHARJO VILLAGE}

\footnotetext{
ABSTRACT

One of the renewable energy sources is water (hydro) energy. Where water (hydro) energy utilization is targeted to reach 4\% of national energy use in 2025. To reach these targets, it is necessary to increase the utilization of water resources (hydro) which are spread throughout Indonesia as a renewable energy source. One of the promising categories of utilization of water resources as renewable energy (electricity) is Micro Hydro Power Plant (MHP) (Marfudin, 2016). Waterwheel is a means to convert water energy into mechanical energy in the form of torque on the
} 
wheel shaft. Breastshot water wheel is a combination of overshot and undershot types seen from the energy they receive.

Data was collected in Palemadu Hamlet, Sriharjo Village, Imogiri Subdistrict, Bantul Regency, Yogyakarta due to the absence of previous data, the researcher conducted an observation and literature method by measuring irrational flow velocity before entering the mill, and the main size of the water mill.

The total energy produced by the Breashshot water wheel on an irrigation channel with an efficiency is $50.49 \%$ with a flow rate is $1.8 \mathrm{m3} / \mathrm{s}$, head is 0.3 water density $1000 \mathrm{~kg} / \mathrm{m} 3$ and a gravity is 9.81 obtained by electric power amounting to is 267.46 watts. With a total power is 267.46 watts included in the type of Picohidro Hydroelectric Power Plant, where picohidro electric power is $<500$ watts. Sriharjo Village is a village located in the area of ecotourism and agriculture. Power generated from Breastshot water wheels are not just for street lighting, they can also be used to repel pests that attack rice farmers.

Keyword: Potential studies, flow rate, discharge, waterwheel, irrigation channels, ecotourism. 


\section{Pendahuluan}

Energi mempunyai peranan penting dalam pencapaian tujuan sosial, ekonomi dan lingkungan untuk pembangunan berkelanjutan serta merupakan aspek pendukung bagi kegiatan ekonomi nasional. Penggunaan energi di Indonesia meningkat pesat seiring dengan pertumbuhan ekonomi dan pertambahan jumlah penduduk. Sedangkan akses menuju energi yang andal dan terjangkau merupakan pra-syarat utama untuk meningkatkan standar hidup masyarakat.

Kebutuhan energi di Indonesia saat ini masih didominasi oleh energi yang berbasis bahan bakar fossil, seperti minyak bumi, batu bara dan gas. Kerugian dari bahan bakar tersebut adalah sifatnya yang tidak ramah lingkungan, karena hasil pembakaran bahan bakar fossil adalah $\mathrm{CO}_{2}$ yang merupakan gas rumah kaca. Selain itu bahan bakar fossil merupakan energi yang tak terbarukan, sehingga jika dieksploitasi terus menerus, maka cadangan bahan bakar fossil akan habis. Atas dasar pertimbangan tersebut maka pemerintah melalui peraturan Presiden No. 5 Tahun 2006 telah menetapkan target energi baru terbarukan dalam bauran energi nasional minimal 17\%. Berdasarkan Kebijakan Energi Nasional yang baru, pangsa energi primer yang berasal dari sumber energi baru terbarukan sebesar $25 \%$ ditetapkan menjadi target. Dengan target tersebut maka mengharuskan penggunaan energi baru terbarukan secara maksimal (Windarti Menik, 2014).

Salah satu sumber energi terbarukan yaitu energi air (hidro). Dimana pemanfaatan energi air (hidro) ditargetkan mencapai $4 \%$ dari penggunaan energi nasional pada tahun 2025. Untuk memenuhi target tersebut maka perlu ditingkatkan dalam pemanfaatan sumber daya air (hidro) yang tersebar di seluruh wilayah di Indonesia sebagai sumber energi terbarukan. Salah satu kategori pemanfaatan sumber daya air sebagai energi terbarukan (energi listrik) yang sangat menjanjikan adalah Pembangkit Listrik Tenaga Mikro Hidro (PLTMH) (Marfudin, 2016)

Mikrohidro adalah istilah yang digunakan untuk instalasi pembangkit listrik yang menggunakan energi air. Kondisi air yang bisa dimanfaatkan sebagai sumber daya (resources) penghasil listrik adalah memiliki kapasitas aliran dan ketinggian tertentu dan instalasi. Semakin besar kapasitas aliran maupun ketinggiannya dari instalasi maka semakin besar energi yang bisa dimanfaatkan untuk menghasilkan energi listrik. Mikrohidro juga dikenal sebagai white resources dengan kelemahan bebas bisa dikatakan "energi putih". Dikatakan demikian karena instalasi 
pembangkit listrik seperti ini menggunakan sumber daya yang telah disediakan oleh alam dan ramah lingkungan. Suatu kenyataan bahwa alam memiliki air terjun atau jenis lainnya yang menjadi tempat air mengalir. Dengan teknologi sekarang maka energi aliran air beserta energi perbedaan ketinggiannya dengan daerah tertentu (tempat instalasi akan dibangun) dapat diubah menjadi energi listrik (Chadidjah Siti dan Wiyoto, 2011).

Kincir air merupakan sarana untuk merubah energi air menjadi energi mekanik berupa torsi pada poros kincir. Kincir air Breastshoot water wheel merupakan perpaduan antara tipe overshoot dan undershoot dilihat dari energi yang diterimanya. Jarak tinggi jatuhnya tidak melebihi diameter kincir, arah aliran air yang menggerakkan kincir air disekitar sumbu poros dari kincir air. Kincir air jenis ini menperbaiki kinerja dari kincir air tipe undershoot.

Pemanfaatan selain untuk pembangkit listrik fungsi bendung juga sebagai irigasi. Suatu pertanian untuk mendapatkan hasil yang baik, maka diperlukan adanya irigasi. Air untuk irigasi ini dapat berasal dari hujan maupun air permukaan. Tanaman padi merupakan jenis tanaman yang membutuhkan banyak air untuk tumbuh dan berkembang, dengan mengetahui jumlah air yang diperlukan untuk kehidupan tanaman pada masing-masing areal pertanian, maka dapat dicapai pembagian air yang merata dan mencukupi. Artinya air irigasi yang di alirkan ke areal sawah tersebut disesuaikan dengan kebutuhan pertaniannya.

Lokasi penelitian ini pada saluran irigasi Desa Sriharjo Kecamatan Imogiri Kabupaten Bantul Provinsi DI. Yogyakarta. Kincir air Breastshot water wheel jenis yang tepat untuk diterapkan pada lokasi penelitian.

\subsection{Rumusan masalah}

Melihat kondisi yang ada pada lokasi penelitian Di Desa Sriharjo maka ada beberapa permasalahan yang dibahas, antara lain :

1. Bagaimana potensi debit dan tinggi jatuh air di saluran irigasi Desa Sriharjo ?

2. Bagaimana memilih jenis kincir yang sesuai dengan debit dan tinggi jatuh air yang ada di desa Sriharjo ?

3. Bagaimana menghitung total energi listrik yang dihasilkan dari kincir air di saluran irigasi desa Sriharjo ?

\section{TINJAUAN PUSTAKA}

Pembangkit Listrik Tenaga Mikrohidro (PLMTH), biasa disebut mikrohidro, adalah suatu pembangkit listrik skla kecil yang menggunakan tenaga air sebagai penggeraknya, misalnya saluran irigasi, suangai atau air terjun alam, dengan cara 
memanfaatkan tinggi, terjunannya (head dalam meter) dan jumlah debit airnya $\left(\mathrm{m}^{3} / \mathrm{dt}\right)$. Umumnya PLTMH yang dibangun jenis run off river dimana head diperoleh tidak dengan membangun bendungan besar, melainkan dengan mengalihkan aliran air sungai ke satu sisi dari sungai dan menjatuhkannya lagi kesungai pada suatu tempat dimana beda tinggi yang diperlukan sudah diperoleh, dengan menggunakan pipa. Air dialirkan ke power house (rumah pembangkit) yng biasanya di bangun dipinggir sungai. Melalui nosel air akan menyemprot keluar memutar roda turbin (runner), kemudian air tersebut dikembalikan ke sungai asal. Energi mekanik putaran poros turbin akan diubah menjadi energi listrik oleh sebuah generator.

Pembangkit listrik tenaga air dibawah ukuran $200 \mathrm{KW}$ digolongkan sebagai PLTMH (mikrohidro). Dalam perencanaan pembangunan sebuah PLTMH, diperlukan pengetahuan tentang :
a. Hidrologi
b. Kelistrikan
c. Bangunan sipil
d. Permesianan
e. Ekonomi untuk studi kelayakan

Pembangunan PLMTH, yang lebih dikenal dengan mikrohidro, beranjak dari konsep :

a. Memanfaatkan energi air yang melimpah agar dapat dilakukan penghematan sumber energi lain seperti minyak bumi dan kayu bakar.

b. Penggunaan listrik yang dihasilkan diarahkan untuk pemakaian yang bersifat produktif agar dapat mendorong aktifitas ekonomi pedesaan.

c. Penggunaan dan pengelolaan PLTMH oleh masyarakat pedesaan merupakan media bagi usaha pengembangan masyarakat.

Kincir air atau water wheel merupakan PLTA yang mempunyai konstruksi sederhana. Terdiri dari roda atau drum di mana pada sepanjang kelilingnya dipasang sudut-sudut yang berupa bilah. Bilah tersebut yang menerima pukulan air yang diteruskan ke roda atau drum dan langsung kepada poros kincir. Bentuk sudut atau bilah ada bermacam-macam, ada yang berbentuk lengkung, siku-siku dan ada pula yang hanya lurus saja.

Kincir air Breastshot merupakan perpaduan antara tipe overshot dan undershot dilihat dari energi yang diterimanya. Jarak tinggi jatuhnya tidak melebihi diameter kincir, arah aliran air yang menggerakkan kincir air disekitar sumbu poros dari kincir air. Kincir air jenis ini menperbaiki kinerja dari kincir air tipe undershot.

\subsection{Aspek Teknologi}

$\begin{array}{lrr}\quad \text { Dari } & \text { segi teknologi } & \text { PLTMH } \\ \text { memiliki } & \text { keuntungan } & \text { dan } \\ \text { kemudahan } & \text { dibandingkan }\end{array}$


pembangkit listrik lainnya. Hal tersebut karena :

a. Kontruksi relatif sederharna.

b. Teknologi mikrohidro telah matang dan terjamin sebagai teknologi yang dapat dikontrol dan dikelola secara mendiri oleh masyarakat pedesaan.

c. Mudah dalam perawatan dan penyediaan suku cadang, karena hampir semua komponen yang diburuhkan telah dapat diproduksi di dalam negeri.

d. Dapat dioprasikan dan dirawat oleh masyarakat di desa.

e. Biaya operasi dan perawatan rendah.

\subsection{Aspek Lingkungan}

PLTMH ramah terhadap
lingkungan, karena tidak
menghasilkan gas buangan atau
limbah lainnya, dan tidak merusak
ekosistem sungai. Dengan demikian,
kelebihan PLTMH dari segi
lingkungan adalah:

a. Mengurangi pemakaian bahan bakar fosil untuk penerangan dan kegiatan rumah tangga seperti memasak, contoh : minyak tanah, solar, kayu bakar.

b. Terpeliharannya daerah tangkapan air, untuk menjamin suplai air bagi kelangsungan PLTMH

c. Ramah terhadap lingkungan.

\subsection{Aspek Sosial Ekonomi}

Kehadiran PLTMH disuatu kawasan pariwisata akan meningkatkan interaksi sosial dan menumbuhkan aktifitas- aktifitas perekonomian baru. Dari sudut pandang ini kelebihan PLTMH adalah :

a. Mendorong aktivitas perekonomian dikawasan pariwisata dengan cara.meningkatkan produktivitas melalui industri rumahtangga yang lebih moderen

b. Menciptakan lapangan kerja baru.

c. Pelayanan kepada pengunjung dan masyarakat sekitar dalam bentuk penerangan.

d. Mendorong Lembaga Desa (misalnya KUD) untuk berperan dalam pengelolaan dan pengoperasian PLTMH.

e. Mikrohidro menyediakan peluang untuk investasi dan manufaktur bagi masyarakat sekitar.

\subsection{Aspek}

Lembaga

\section{Kemasyarakatan}

Pengoprasian PLTMH menuntut adanya suatu lembaga yang menjalankan fungsi -fungsi pengelolaan dan perawtan. Lembaga tersebut akan menambahkan keberadaan lembaga yang sudah ada didesa. Dinamika masyarakat akan berkembang dan keuntungan yng diperoleh adalah :
a. Partisipasi
lokal dalam
pembuatan keputusan danmanajemen lokal dari 
pelistrikan pedesaan adalah dimungkinkan denga melalui PLTMH.

b. Peningkatan peran pemerintah desa dan lembaga lainnya.

\section{METODE PENELITIAN}

Secara garis besar, tahapan penelitian diperlihatkan dalam bentuk diagram alair pada Gambar 3.1 Tahapan-tahapan penelitian tersebut adalah:

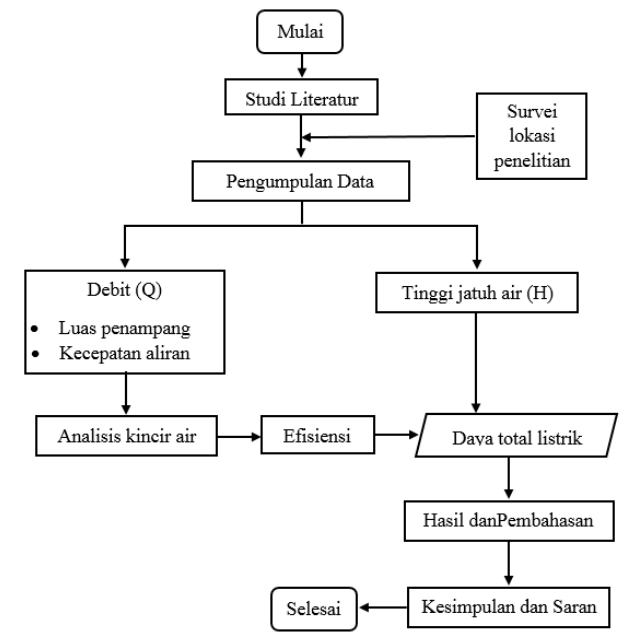

Gambar 3.1 Diagram alir penelitian

a. Studi literatur

Pada penelitan ini dilakukan studi literatur mengenai Pembangkit listrik tenaga air, turbin air, Kincir air, Klasifikasi turbin air, debit, tinggi jatuh air (head), dan energi listrik yang dapat dibangkitkan oleh sebuah kincir air.

b. Survei Lokasi

Survei lokasi dilakukan di saluran irigasi Dusun Palemadu, Desa Sriharjo. c. Pengumpulan data berupa data primer debit dan tinggi jatuh air (head) yang diambil langsung di lokasi saluran irigasi Dusun Palemadu, Desa Sriharjo.

d. Analisis data

Data-data hasil pengukuran kemudian dianalisa untuk mengetahui potensi yang ada pada saluran irigasi Dusun Palemadu, Desa Sriharjo. Selanjutnya memilih jenis kincir air dan merancang dimensi berdasarkan debit dan tinggi jatuh air (head) yang dimiliki.

e. Penulisan laporan

Penulisan laporan adalah akhir dari penelitian ini.

\section{HASIL DAN PEMBAHASAN}

\subsection{Hasil penelitian}

Penelitian yang dilakukan pada tanggal 24 September 2018 30 Januari 2019 di Dusun Palemadu Desa Sriharjo Kecamatan Imogiri kabupaten Bantul Yogyakarta dengan titik koordinat $7^{0} 56$ '32'S $110^{0} 22^{\prime} 08^{\prime \prime E}$. Pengukuran dilakukan sebanyak 8 kali dan tidak mempunyai data sebelumnya maka peneliti melakukan metode observasi dan kepustakaan.

Dari hasil pengukuran sebanyak 8 kali pengambilan data dimana, kecepatan aliran irirgasi sebelum masuk kincir, dan desain kincir air, adapun data umum sebagai berikut: 
Tabel 4.1 hasil pengukuran pada saluran irigasi

\begin{tabular}{|clc|}
\hline No & Jenis pengukuran & $\begin{array}{c}\text { Hasil } \\
\text { pengukuran }\end{array}$ \\
\hline 1 & Panjang Saluran & $210 \mathrm{~cm}$ \\
\hline 2 & Lebar Saluran & $50 \mathrm{~cm}$ \\
\hline 3 & Beda tinggi jatuh air & $30 \mathrm{~cm}$ \\
\hline 4 & Tebal saluran & $30 \mathrm{~cm}$ \\
\hline
\end{tabular}

Tabel 4.2 hasil pengukuran kecepatan aliran pada saluran irigasi

\begin{tabular}{|c|c|c|c|c|c|c|}
\hline \multirow{3}{*}{ No } & \multirow{3}{*}{ Bulan } & \multicolumn{4}{|c|}{$\begin{array}{l}\text { Kecepatan aliran } \\
\mathrm{m}^{3} / \mathrm{s}\end{array}$} & \multirow{3}{*}{$\begin{array}{l}\text { Rata- } \\
\text { rata }\end{array}$} \\
\hline & & \multicolumn{4}{|c|}{ Minggu } & \\
\hline & & 1 & 2 & 3 & 4 & \\
\hline 1. & September & 1,9 & 1,6 & 1,8 & 1,9 & 1,8 \\
\hline 2. & Januari & 1,9 & 1,7 & 1,8 & 1,9 & 1,8 \\
\hline \multicolumn{6}{|c|}{ total } & 1,8 \\
\hline
\end{tabular}

Penurunan kecepatan aliran dikarenakan sampah yang menumpuk di pintu air sehingga menghambat laju air.

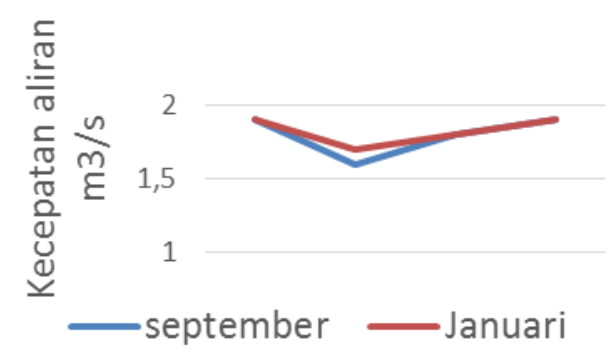

Gambar 4.3 Diagram kecepatan

aliran pada saluran irigasi

Berdasarkan gambar 4.3 dapat dilihat bahwa kecepatan aliran pada bulan september mengalami penurunan yang signifikan $0,3 \quad \mathrm{~m}^{3} / \mathrm{s}$ dibandingkan dengan bulan januari sebesar $0,2 \mathrm{~m}^{3} / \mathrm{s}$.
Kincir air yang digunakan untuk penelitian ini menggunakan jenis breastshot water wheel dilihat dari arah masuknya air dari tengahtengah diameter kincir yang mendorong sudu pada kincir air. Berdasarkan struktur bangunan pada saluran irigasi dapat dilihat posisi kincir yang akan di gunakan. Sebagai berikut :

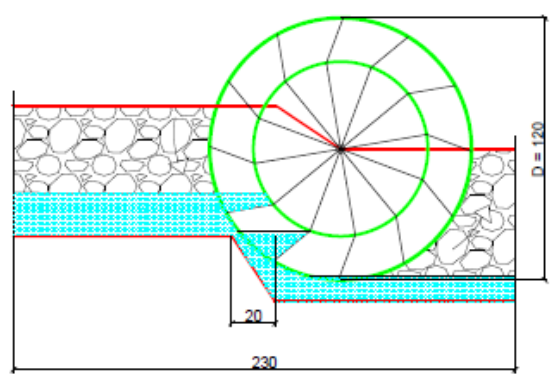

Gambar 4.1 Desainkincir pada

saluran irigasi tampak samping

Hasil dari pengukuran saluran irigasi menentukan desain kincir air yang dibuat. Hasil pengukuran kincir air yang diperoleh sebagai berikut :

Tampak samping

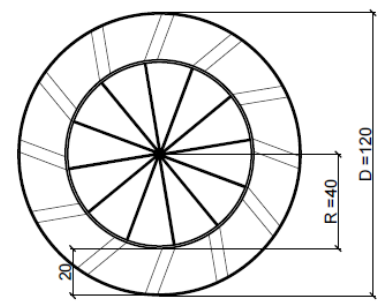

Gambar 4.2 desain kincir air tampak samping

\subsection{Kincir air}




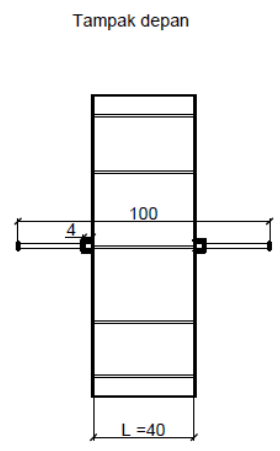

Gambar 4.3 Desain kincir air tampak depan

Sudu kincir air
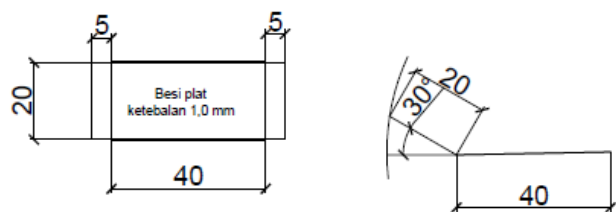

Gambar 4.4 Desain sudu pada kincir air

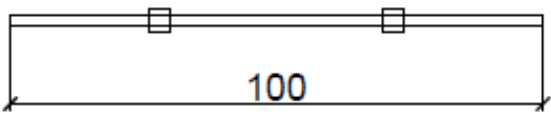

AS kincir air

Gambar 4.5 Desain As kincir air

Tabel 4.4 Pengukuran kincir air

\begin{tabular}{|c|l|c|}
\hline No & \multicolumn{1}{|c|}{ Jenis pengukuran } & $\begin{array}{c}\text { Hasil } \\
\text { pengukuran }\end{array}$ \\
\hline 1. & Diameter luar kincir & $120 \mathrm{~cm}$ \\
\hline 2. & Diameter dalam kincir & $40 \mathrm{~cm}$ \\
\hline 3. & Jumlah sudu & $12 \mathrm{buah}$ \\
\hline 4. & Sudut Sudu & $30^{0}$ \\
\hline 5. & Lebar sudu & $40 \mathrm{~cm}$ \\
\hline 6. & Tinggi sudu & $20 \mathrm{~cm}$ \\
\hline 7. & Lebar kincir & $40 \mathrm{~cm}$ \\
\hline 8. & Panjang as kincir & 100 \\
\hline
\end{tabular}

Pengambilan sampel yang dilakukan dalam penelitian ini pada saluran irigasi di Dusun Palemadu Desa Sriharjo Kecamatan Imogiri dengan titik koordinat $7^{0} \quad 56$ '32's $110^{0} 22^{\prime} 08^{\prime}$ E. Berikut adalah hasil uji laboratorium.

Tabel 4.6 Hasil uji laboratorium

\begin{tabular}{|l|l|c|c|}
\hline No. & Parameter & Satuan & $\begin{array}{c}\text { Hasil } \\
\text { Pengujian }\end{array}$ \\
\hline 1. & $\mathrm{Fe}$ & $\mathrm{mg} / \mathrm{l}$ & 0,4 \\
\hline 2. & TSS & $\mathrm{Mg} / \mathrm{l}$ & 206 \\
\hline
\end{tabular}

Berdasarkan hasil uji laboratorium dapat dilihat pada tabel 4.6 bahwa nilai TSS sebesar Menurut Peraturan Pemerintah Republik Indonesia No. 82 tahun 2001 standar baku mutu air (BMA) kelas II yang memiliki nilai maksimum $50 \mathrm{mg} / \mathrm{l}$. Dengan nilai TSS diatas rata-rata berpotensi terjadinya sedimentasi pada dasar permukaan aluran irigasi, yang menyebabkan penyempitan pada saluran irigasi.

Selain parameter TSS peneliti juga menggunakan parameter $\mathrm{Fe}$ untuk mengatuhi dampak terhadap bahan yang digunakan dalam pembuatan kincir air yang akan dirancang. Dengan nilai Fe 0,4 yang cukup rendah sehingga peneliti menggunakan bahan untuk pebuatan kincir air dari besi.

\subsection{Perhitungan dan pembahasan}

Perhitungan dimulai dengan menghitung kecepatan aliran air data pada tabel 4.2 , kemudian dilanjutkan dengan menghitung luas penampang 
pada saluran, debit, daya air, torsi, daya kincir, efisiensi, dan daya total. Berikut perhitungannya :

a. Luas penampang saluran irigasi

$$
\begin{aligned}
A \quad & =b \times h \text { (tinggi permukaan air }) \\
& =0,5 \times 0,2 \\
& =0,1 \mathrm{~m}^{2}
\end{aligned}
$$

b.

Debit air

pada saluran irigasi

$$
\begin{aligned}
Q & =V \times A \\
& =1,8 \times 0,1 \\
& =0,18 \mathrm{~m}^{3} / \text { detik } \\
& =180 \text { liter } / \text { detik }
\end{aligned}
$$

$$
\begin{aligned}
\text { c. } & \\
P_{\text {air }} & =\rho \times g \times Q \times h \quad \text { Daya air } \\
& =1000 \times 9,81 \times 0,18 \times 0,3 \\
& =529,74 \text { Watt }
\end{aligned}
$$

d. Gaya fluida yang mengenai sudu

$$
\begin{aligned}
\mathrm{F} & =\rho \times \mathrm{A} \mathrm{x} \mathrm{v}^{2} \\
& =1.000 \mathrm{~kg} / \mathrm{m} 3 \times 0,08 \times 1,8^{2} \\
& =259,2 \mathrm{~N}
\end{aligned}
$$

e. Jumlah rotasi pada kincir air.

$$
\begin{aligned}
\mathrm{n} & =\frac{60 x v}{\pi x D} \\
& =\frac{60 x 1,8}{3,14 \times 1,2} \\
& =28,6 \mathrm{~s}
\end{aligned}
$$

\begin{tabular}{|c|c|c|}
\hline No. & Parameter & Hasil \\
\hline 1. & $\begin{array}{l}\text { Luas penampang saluran } \\
\text { irigasi (A) }\end{array}$ & $0,1 \mathrm{~m}^{2}$ \\
\hline 2. & Debit $(\mathrm{Q})$ & $0,18 \mathrm{~m}^{3} / \mathrm{s}$ \\
\hline 3. & Daya air $\left(\mathrm{P}_{\mathrm{air}}\right)$ & $\begin{array}{l}529,74 \\
\text { watt }\end{array}$ \\
\hline 4. & $\begin{array}{l}\text { Gaya fluida yang } \\
\text { mengenai sudu ( } \mathrm{F} \text { ) }\end{array}$ & $259,2 \mathrm{~N}$ \\
\hline 5. & Torsi $(\mathrm{T})$ & $\begin{array}{l}155,52 \\
\text { N.m }\end{array}$ \\
\hline 6. & Rotasi kincir air ( n ) & $28,6 \mathrm{~s}$ \\
\hline 7. & $\begin{array}{l}\text { Kecepatan sudu kincir } \\
(\omega)\end{array}$ & $1,72 \mathrm{rad} / \mathrm{s}$ \\
\hline 8. & Daya kincir $\left(\mathrm{P}_{\text {kincir }}\right)$ & $\begin{array}{c}267,50 \\
\text { watt }\end{array}$ \\
\hline 9. & Efiisiensi ( $\prod$ ) & $50,49 \%$ \\
\hline 10. & Daya total $\left(\mathrm{P}_{\text {total }}\right)$ & $\begin{array}{c}267,46 \\
\text { watt }\end{array}$ \\
\hline
\end{tabular}

f. Kecepatan sudu kincir

$$
\begin{aligned}
\omega & =\frac{2 v n(\text { kincir })}{60} \\
& =\frac{2 \times 1,8 \times 28,6}{60} \\
& =1,72 \mathrm{rad} / \mathrm{s}
\end{aligned}
$$

g. Daya kincir

$$
\begin{aligned}
P_{\text {kincir }} & =\mathrm{T} \times \omega \\
& =155,52 \times 1,72 \\
& =267,50 \text { watt }
\end{aligned}
$$

h. Efisiensi

$$
\begin{aligned}
\eta & =\frac{P \text { kincir }}{P \text { air }} \times 100 \% \\
& =\frac{267,50}{529,74} \times 100 \% \\
& =50,49 \%
\end{aligned}
$$

i. Daya total

$$
\begin{aligned}
\mathrm{P}_{\text {total }} & =\eta \times \rho \times g \times Q \times H \\
& =50,49 \% \times 1000 \times 9,81 \times \\
& 0,18 \times 0,3 \\
& =267,46 \mathrm{watt}
\end{aligned}
$$

Dari data yang diperoleh dari hasil pengukuran kemudian di analisis data dan didapatkan beberapa hasil seperti tabel 4.5 sebagai berikut :

Tabel 4.5 ringkasan hasil analisis data.

Daya total energi yang dihasilkan dari kincir air jenis Breashshot water wheel pada saluran 
irigasi dengan efisiensi 50,49\% dengan kecepatan aliran $1,8 \mathrm{~m}^{3} / \mathrm{s}$, head 0,3 massa jenis air $1000 \mathrm{~kg} / \mathrm{m}^{3}$ dan gaya grafitasi 9,81 diperoleh daya listrik sebesar 267,46 watt. Dengan daya total sebesar 267,46 watt termasuk dalam jenis Pembangkit Listrik Tenaga Air Picohidroberdasarkan tabel 4.6 dibawah, dimana daya listrik picohidro $<500$ watt.

Tabel 4.6 Klasifikasi kincir air berdasarkan kapasitas.

\begin{tabular}{|l|l|l|}
\hline No. & Jenis tenaga air & \multicolumn{1}{c|}{ Kapasitas } \\
\hline 1. & PLTA Pico & $<500 \mathrm{~W}$ \\
\hline 2. & PLTA Micro & $0,5-100 \mathrm{KW}$ \\
\hline 3. & PLTA mini & $100-1000 \mathrm{KW}$ \\
\hline $\mathbf{4 .}$ & PLTA kecil & $1-10 \mathrm{MW}$ \\
\hline $\mathbf{5 .}$ & $\begin{array}{l}\text { PLTA skala } \\
\text { penuh }\end{array}$ & $>10 \mathrm{MW}$ \\
\hline
\end{tabular}

Studi potensi ini dirancang untuk optimalisasi potensi energi dan pemanfatan sumber daya air pada saluran irigasi di Desa Sriharjo mampu meningkatkan kebutuhan energi listrik untuk kawasan ekowisata. Menurut (Abdur rohman, 2009) ada empat aspek dalam optimalisasi potensi energi sekaligus potensi wisata, yaitu : aspek konservasi, aspek edukasi, aspek sosial, dan aspek ekonomi. Energi baru terbarukan telah memenuhi aspek-aspek tersebut.

Desa Sriharjo merupakan Desa yang berada dikawasan ekowisata dan pertanian. Daya yang dihasilkan dari kincir air Breastshot water wheel bukan hanya utuk lampu penerangan jalan saja, bisa juga digunakan untuk mengusir hama yang menyerang padi para petani. Dimana yang telah diterapkan para peteani di Kabupaten Brebes Jawa tengah.

Para petani memasang lampu ditengah-tengah lahan pertanian mereka. Lampu-lampu tersebut bisa dipakai petani bawang merah sebagai alat penangkap organisme pengganggu tanaman, dengan di bawahnya diletakkan baskom air yang dicampur minyak kelapa . Cahanya yang terang saat malam hari menarik hama yang umumnya serangga, masuk kedalam perangkap. Sama halnya para petani di Desa Sriharjo terutama di Dusun Palemadu yang dekat dengan lokasi penelitian, sehingga bisa diterapkan dikawasan ini. Untuk meningkatkan hasil pertanian dan menjadi wisata edukasi.

\section{KESIMPULAN DAN SARAN}

\subsection{Kesimpulan}

Berdasarkan penelitian yang telah dilakukan pada saluran irigasi didapatkan data pencatatan kecepatan aliran, debit, luas penampang pada saluran irigasi,dan perhitungan kincir air jenis breastshot water wheel, maka dapat diambil berbagai kesimpulan sebagai berikut :

1. Dengan luas penampang pada saluran irigasi $0,1 \mathrm{~m}$, tinggi jatuh air $0,3 \mathrm{~m}$, dan kecepatan aliran 
$1,8 \mathrm{~m}^{3} / \mathrm{s} 0,3$ diperoleh debit air sebesar.adalah $0,18 \mathrm{~m}^{3} / \mathrm{s}$.

2. Debit sebesar $0,18 \mathrm{~m}^{3} / \mathrm{s}$ dan tinggi jatuh air 0,3 m, digunakan jeniskincir Breashtshot water wheel.

3. Daya total hasil dari analisis data di dapatkan hasil sbesar 267,46 watt.

\subsection{Saran}

Saran yang dapat diberikan untuk penelitian "Studi Potensi Dan Tinggi Jatuh Air Pada Saluran Irigasi Untuk Mendukung Kebutuhan Energi Listrik Kawasan Ekowisata Di Desa Sriharjo" adalah sebagai berikut:

1. Untuk selanjutnya yang menlanjutkan studi potensi pada lokasi yang sama hendaknya melakukan pengukuran debit maksimal pada lokasi tersebut sehingga dapat menghitung daya terbesar.

2. Sebagai acuan penelitian selanjutnya untuk pembuatan desain sesuai dengan studi potensi yang telah dilakukan sebelumnya.

\section{DAFTAR PUSTAKA}

Anonim. Manual Pembangunan Pltmh. Japan International Cooperation Agency. People Centered Business And Economi Institute.

Gandakoesoemah, R. 1975. Irigasi .Sumur Bandung. Bandung.
Himran Syukri.2017. Turbin air, Teori dan Dasar Perencanaan. Andi.

Mafruddin. $2016 . \quad$ Studi Eksperimental Sudut Nosel Dan Sudut Sudut Terhadap Kinerja Turbin Cross-Flow Sebagai Pltmh Di Desa Bumi Nabung Timur. Program Pascasarjana Magister Teknik Mesin. Fakultas Teknik. Universitas Lampung. Bandar Lampung.

Nasution, Ridwan Ichwan. 2005. Aliran Seragam Pada Saluran Terbuka Teori \&

Penyelesaian Soal-Soal.

Fakultas Teknik. Jurusan

Teknik Sipil. Universitas

Sumatera Utara.

Peraturan Menteri Dalam Negeri Nomor 33 Tahun 2009 : tentang pedoman pengembangan ekowisata di daerah, telah mendorong pemerintah daerah untuk mengembangkan ekowisata yang belakangan ini telah menjadi trend dlam kegiatan kepariwisataan Indonesia.

Rakasiwi, Abryan Dkk. 2016. Pengaruh Sudu-Sudu Pada Model Kincir Air Undershot Untuk Irigasi Pertanian. Jurusan Teknik Sipil. Fakultas Teknik. Universitas Riau. Pekanbaru.

Rangga Raju. K. G. Aliran Melalui Saluran Terbuka. Erlangga. 
Shaufi, Fiqri.Studi Potensi Pembangkit Listrik Tenaga Mikro Hidro (Pltmh) Berbantuan Program Casimir Di Riam Pagung Desa Sanatab Kecamatan Sajingan Besar Kabupaten Sambas.Jurusan Teknik Elektro. Fakultas Teknik. Universitas Tanjungpura. Tanjungpura.

Sihaloh Bernadictus. 2017. Performance Of A Breastshot Waterwheel With A 120 Degree Blade. Universitas Sanata Dharma. Yogyakarta.

Rohman Abdur. 2009. Studi Perumusan Alternatif Skema Pembangkit Listrik Tenaga Mikrohiro (PLTMH) Untuk Optimalisasi Potensi Energi dan Potensi Wisata Curug Cimahi. Program Studi Teknik Tenaga Listrik. Institut Teknologi Bandung. Bandung.

Soewarno. 1991. Hidrologi Pengukuran Dan Pengolahan Data Aliran Sungai (Hidrometri). Penerbit Nova. Bandung.

Streeter, Victor.L and Wylie, E. Benjamin. 1996. Mekanika Fluida. Penerbit Erlangga. Jakarta.

Suwachid. 2006. Ilmu Turbin. Uns Press. Surakarta.

Wahyono Wibowo. 2002. Kincir Air Pembangkit Listrik.
Universitas Sanata Dharma. Yogyakarta.

Windarti, Menik. 2014. Potensi Debit Air Bendung Tegal Untuk Pembangkit Listrik Tenaga Mikrohidro (Pltmh) Dan Irigasi Di Desa Kebonagung Dan Desa Sriharjo Kecamatan Imogiri Kabupaten Bantul. Jurusan Pendidikan Geograf Fakultas Ilmu Sosial. Universitas Negeri Yogyakara. Yogyakarta.

Yusri. 2004. Analisis Daya dan Putaran Kincir Air Tradisional Sebagai Alternatif Sumber Daya Penggerak. Politeknik Negeri Padang. Padang. 
